\title{
1. Integrating the environment for sustainable development: an introduction
}

\author{
Andrew Jordan and Andrea Lenschow
}

At a public hearing organized by the World Commission on Environment and Development (WCED) in May 1986, the former Canadian federal minister of the environment, Charles Caccia, asked a deceptively simple question: 'How long can we go on and safely pretend that the environment is not the economy, is not health, is not the prerequisite to development, is not recreation?' (quoted in WCED 1987: 38). He firmly believed that new ways had to be found to ensure that environmental thinking was a part of all these things, if society genuinely wanted to develop more sustainably. But how could and, just as importantly, should this be achieved?

This line of thinking evidently influenced the WCED because in the first few pages of its landmark report - Our Common Future - it remarked that:

Those responsible for managing natural resources and protecting the environment are institutionally separated from those responsible for managing the economy. The real world of interlocked economic and ecological systems will not change; the policies and institutions concerned must (ibid.: 9) (emphasis added).

In a later section, it tried to explain more precisely how 'policies and institutions' should change:

The major central economic and sectoral agencies of governments should now be made directly responsible and fully accountable for ensuring that their policies, programmes and budgets support development that is ecologically, as well as economically sustainable (ibid.: 314 ).

Although the WCED did not use the term 'environmental policy integration' (or EPI), these paragraphs effectively introduced it to a global audience. Since 1987, EPI has received widespread political backing internationally, but especially in the European Union (EU), where it now has a prominent legal status in the founding Treaties. At EU level and in many Member 
States, EPI is regarded as a key element of the transition to sustainability (Jordan 2008). In fact, one of us has referred to EPI as a 'first-order operational principle to implement and institutionalize the idea of sustainable development' in the manner popularized by Gro Harlem Brundtland's World Commission (Lenschow 2002a: 6). ${ }^{1}$

The verb 'to innovate' means to introduce something new, or to change fundamentally something that is already well established. In the past, environmental policy has tended to be a rather reactive exercise in remedying the environmental damage generated by sectoral policies such as the intensification of agricultural production or the construction of new transport infrastructure. If EPI was implemented in the manner described by Charles Caccia or Brundtland's World Commission, it would - as the title of this book suggests - represent a very significant innovation in the way in which environmental policy has traditionally been thought about and implemented. Liberatore (1997: 107) made this point very succinctly over a decade ago:

The relevance of [EPI] for moving towards sustainable development is straightforward: if environmental factors are not taken into consideration in the formulation and implementation of the policies that regulate economic activities and other forms of social organization, a new model of development that can be environmentally and socially sustainable in the long term cannot be achieved.

EPI - at least as the Brundtland Report perceived it - aims to turn the policy status quo on its head, so that in future, environmental protection involves a much more holistic and, above all, proactive search early on in the policy process for opportunities to prevent environmental damage from occurring. Lafferty and Hovden (2003: 2) argue that such a change would be innovative in the sense that it would constitute 'a relatively strong revision of the traditional hierarchy of policy objectives, where environmental goals and values historically have tended to be at the lower end of the scale'.

But more than twenty years after the publication of Our Common Future, the majority of political systems seem no closer to institutionalizing EPI in the manner elegantly set out by Mrs Brundtland or Mr Caccia. In many respects, they appear to have moved further away, even in Europe. In 2003, the European Environment Agency (EEA) (EEA 2003: 7) concluded that 'the implementation of more integrated approaches to policy making needs to be accelerated if Europe is . . . to meet its aspirations on sectoral integration and sustainable development'. ${ }^{2}$ In 2007, the European Commission conceded that 'progress has been mixed' and as a consequence 'Europe is not yet on the path towards a genuinely sustainable development' (COM (2007) 225 final, 30-4-07: 15, 4). Some commentators have gone even further, claiming that ' $[\mathrm{t}] \mathrm{he}$ recent overriding concern for growth and jobs 
has been used to call into question the very legitimacy of [EU] regulatory action in many fields, including the environment' (Pallemaerts et al. 2006: ii). In short, integration has not yet reached the degree of normality envisioned by Mrs Brundtland or Mr Caccia. In fact, as policy goals, sustainable development and EPI appear more remote and more politically contested today than they did twenty years ago.

Those looking for a detailed assessment of what has - or has not - been achieved with respect to EPI, can now consult a growing corpus of academic papers and at least two edited books (Lenschow 2002b; Nilsson and Eckerberg 2007). In the 2000s, these were supplemented with a series of policy reviews conducted by the Organisation for Economic Cooperation and Development (OECD) and the European Environment Agency (EEA). Nonetheless, the evidence base underpinning both the concept and the everyday practice of EPI remains relatively fragmented. Considering that the focus on the environmental pillar of sustainable development appears to be a European 'speciality', it is no coincidence that the available literature on EPI has a distinctly European - and, dare we say, even an EU - bias. Unfortunately, detailed country-based research on EPI remains very scarce. ${ }^{3}$ Although there are some excellent overviews (for example, OECD 2002; Jacob and Volkery 2004; EEA 2005a), unlike the literature on governance for sustainable development (Jordan 2008), systematic comparative analyses of EPI are still relatively thin on the ground. Studies of how EPI has been interpreted and implemented in non-European contexts are extremely rare. Similarly, while there are potentially many instruments that can be used to implement EPI, most have either been studied in isolation and/or for other (that is, non-EPI) purposes.

This book aims to address these gaps by bringing together the state of the art in research on EPI conducted at national and supranational levels. It does so by charting the numerous instruments that have been introduced at these two administrative levels since 1987, and analysing the conditions for their effectiveness. In order to do this, we first explore EPI in terms of its conceptual meaning, then we scrutinize the various processes and instruments that can be - or have been - used to put it into effect, and assess the cumulative outcomes of these activities 'on the ground' in different jurisdictions. Thus in Section 2 of this chapter, we begin by discussing the conceptual meaning of EPI that can be inferred from the 'mother document' of sustainable development, namely the Brundtland Report. We also note that in the public discourse in relation to EPI and sustainable development as well as in the application of these concepts, the basic principle of EPI still invites a great variety of different interpretations and, consequently, instruments of implementation. In an early analysis, Weale and Williams (1992: 46) concluded that there was 'no canonical statement 
of precisely what it might involve'. In its stocktaking report, the EEA (2005a: 12) also detected 'little agreement' on its core meaning. In order to permit more systematic analysis, we therefore adopt the economist Keynes's famous distinction between normative and positive definitions, this being a 'pre-requisite for further empirical work' (Lafferty and Hovden 2003: 8-9).

Having done this, Section 3 turns to explore EPI as a governing process. Existing studies identify several factors that influence the scope and the effectiveness of different implementing instruments. Yet little systematic knowledge has emerged. In this book, we identify three broad types of instrument: communicative, organizational and procedural. We set out systematically to investigate them both from a conceptual (or 'textbook') perspective (Part II of this book), and as they have actually been used 'in action' in several key OECD countries (Part III of this book). These instruments, both individually and in combination, delineate the 'game' of EPI in the sense that they define the 'who, when and where' of how different policy choices impact on behaviour. We do so by studying the deployment of different combinations of EPI instruments (namely, administrative instruments, green budgeting, sustainable development strategies, policy appraisal and Strategic Environmental Assessment) and tracking their overall performance in five countries that are generally considered to be pioneers in environmental policy - namely Germany, Norway, Sweden, the UK and the USA - and the European Union (EU). The USA has been remarkably under-studied with regard to EPI, although it was very much a model environmental state in the 1960s and 1970s (Vogel 2005). By contrast, Australia provides another political and institutional setting in which to explore the contemporary processes of EPI.

In Section 3, we suggest two basic perspectives to order our knowledge: a political systems approach and a policy analysis approach. We focus on the European experience, as this is - so far - the main context in which EPI (as opposed to sustainable development) has received serious attention. This is, of course, a gap in the literature that we are also hoping to address in this book (see especially the chapters on the USA and Australia). By proceeding in this way, we try to hold the general political context constant namely, the fundamental acceptance of environmental protection as a goal of policy making - and focus on the strengths and weaknesses of individual instruments from a comparative perspective, as well as taking account of the interplay between different instruments in the context of different political systems.

Finally, Section 4 explains that EPI can also be interpreted as the cumulative outcome of implementing relevant instruments in different policy systems. Although an outcome perspective is not, for reasons that we 
elaborate upon more fully below, the main focus of this book, given our analysis of various policy instruments that have been developed to accomplish EPI, we do have a unique opportunity to begin the process of linking these various EPI instruments to the policy outcomes they have generated 'on the ground' in different jurisdictions. Section 5 concludes this chapter and looks forward to the rest of the book.

Before proceeding any further, we would like to point out that the main purpose of this chapter is not to develop a tight analytical framework and impose it on the empirical chapters, but rather to present a range of standpoints and questions to guide the 'instrument' and 'country' studies respectively. In other words, in this chapter we will pose questions and give analytical direction; answers are expected in the empirical chapters and in Chapter 15.

\section{EPI: NORMATIVE AND POSITIVE CONCEPTUAL MEANINGS}

Many academics and policy makers consider EPI to be a policy-making 'principle' without reflecting too much on precisely what this implies. This may seem like a matter of mere semantics to some, but - especially for lawyers - it is far from trivial as it raises the tricky issues of legal commitment and enforceability (see Hession and Macrory 1998; Nollkaemper 2002). In the EU, the political and legal salience of the principle suggests that the perceived need for clarity is especially important (Nollkaemper 2002: 25-29). If EPI is primarily a policy objective whose role in international, EU and national government documents is to inspire either concrete legal rules or political programmes and activities, it does not form a suitable foundation for legal decisions. Consequently, the EU's commitment will be as enforceable as a United Nations declaration or have the same degree of compulsion as one of the OECD's benchmarks of 'good practice'. If, however, EPI is deemed to have an autonomous meaning and is thus a 'standard to be observed', then a clear definition of the principle's substantive meaning needs to be developed in order for it to be enforceable. But do we actually have agreement on what EPI means?

Lafferty and his colleagues (Lafferty and Hovden 2003; Lafferty 2004; Lafferty and Knudsen 2007) have made the most systematic effort to pin down the core meaning of EPI. Based on a close textual analysis of the international document in which it was first brought to the world's attention - the Brundtland Report - they argue that the WCED's 'mother concept' - sustainable development - attributed 'principled priority' to environmental objectives in the process of 'balancing' economic, social 
and environmental concerns. In other words, the three should not be simply blended together, as this would be little more than 'policy integration'; EPI on the other hand, demands that the environment consistently receives 'special recognition' or 'principled priority' in the decision-making process (Lafferty and Hovden 2003: 9). According to them (ibid.):

The whole point of EPI is . . to avoid situations where environmental degradation becomes subsidiary; and in the context of sustainable development, to ensure that the long-term carrying capacity of nature becomes a principal or overarching societal objective (emphasis added).

In thinking about sustainable development (and thus the view one adopts of how to balance the three concerns), Lafferty and his co-workers designate 'environmental objectives as "trump" in the policy game' (Lafferty and Knudsen 2007: 22) vis-à-vis other policy objectives. The metaphor of 'trump card' in a game called policy, indicates that environmental concerns may lose in individual decisions (that is, if the trump card is not played), but according to a set of more basic 'rules of the game' which prioritize the environment in the sense of 'guarantee[ing] that every effort is made to assess the impact of the [sectoral] policy on the life-sustaining capacities of the affected ecosystem' (ibid.: 25).

This particular reading of EPI implies that it should not mean merely the search for synergy effects and 'win-win' solutions in making sectoral policy choices (that is, the consideration of environmental concerns at no expense to sectoral policy). Nor should it be reduced to a search for a middle ground between three equally valued objectives. Rather, EPI should amount to a deliberate attempt to prioritize the protection of the environment before any trade-offs are made between environmental, economic and/or social objectives. Hence, EPI does not call on environmental policy makers to assess the economic or social impact of environmental policy, but vice versa; the merits of general policy integration notwithstanding, environmental policy integration refers to one-, rather than two-way integration (EEA 2005a: 13). In this perspective, environmental impacts of sectoral decisions may be ignored only if - metaphorically speaking - (environmental) policy makers choose not to use their environmental trump card and instead reserve it for a future decision. Such leeway provided by the rules of the game ensures that trade-off decisions are made in a proportional manner (justifying the otherwise misleading term of 'balancing' in the Brundtland text).

But how has the conceptual link between sustainable development and EPI, with its normative core of prioritizing environmental objectives, been translated into political practice? This chapter will briefly look at the global 
level before turning to the EU and several individual countries which are all covered in the remainder of this book. At a global level, we can observe a (re-) introduction of ambiguity when studying closely Agenda 21, the UN's blueprint for sustainable development. This was the institutional follow-up to the Brundtland Report and was extensively debated prior to being adopted at the 1992 UN Conference on Environment and Development (UNCED). It clearly reflects the political character of the process of implementing sustainable development and hints at the political reluctance to prioritize the environment. '[E]nvironment and development is to be put at the centre of economic and political decision-making' (UNCED 1992: Chapter 8.2, emphasis in original). ${ }^{4}$ Agenda 21 identified four fields of activity to improve the integration of environment and development: (1) integration in policy, planning and at management level (involving the adjustment of institutional structures and procedures as well as the use of data and information instruments); (2) integration by establishing appropriate legal and regulatory frameworks (implying judicial and administrative capacity building to ensure the formulation of effective laws and regulations and their enforcement as well as ongoing monitoring); (3) integration through the use of economic instruments (aiming at a reversal of the tendency to treat the environment as a 'free good' and to ignore the environmental and social cost of economic activity); and (4) integration into environmental and economic accounting (in order to take note more effectively of natural resource use).

But when it came to implementing these activities, Agenda 21 repeatedly emphasized the need to recognize that 'countries will develop their own priorities in accordance with their prevailing conditions, needs, national plans, policies and programmes' (UNCED 1992: Chapters 8.3, 8.4, 8.5, 8.16, 8.31), contradicting Brundtland's argument - summarized in Section 1 of this chapter - that policies and institutions must be changed. Thus, according to Agenda 21, market instruments and information instruments (allowing for flexible national solutions) should aim, among other things, at reducing the 'severe economic and social costs' that environmental standards could impose 'if they are uniformly applied in developing countries' (UNCED 1992: Chapter 8.2). Finally and perhaps most crucially of all, Agenda 21 pointedly refers not to EPI, but to the integration of environmental and developmental concerns into decision making (Chapter 8.2). Later on, it goes one step further by referring to the need to improve the processes of decision making so as to achieve the progressive integration of economic, social and environmental issues in the pursuit of development that is economically efficient, socially equitable and responsible and environmentally sound' (UNCED 1992: Chapter 8.4). Notably absent, therefore, was the clear pledge found 
in Our Common Future to 'integrate the environment for sustainable development'.

Hence, EPI has not been elaborated as a single concept at the global level; we are missing the explicit global pronouncement of rhetorical and operational commitment. On the contrary, Agenda 21 appears to accept that EPI can have a normative meaning and what Keynes would recognize as a series of more positive meanings. The fact that the conceptual meaning of the EPI principle is still contested frustrates lawyers, but it represents an interesting point of departure for comparative policy and political research.

That is to say, we believe that there is value in keeping the debate about the normative meaning of EPI (that is, what kinds of change to existing policy systems it should seek to achieve), apart from but in constant dialogue with the more positive question of how it is actually conceptualized in discourse and implemented in everyday political and policy settings. It is here that we will engage with the issue of priority setting that has attracted a great deal of academic comment, particularly amongst scholars of sustainable development. We will seek to show that while it is necessary to define EPI in normative terms (that is, in terms of the simultaneous pursuit of environmental, economic and social concerns: sustainable development), in the heat of everyday political processes, these interpretations tend to mutate, according to the push and pull of political forces.

Moreover, when and why they mutate should be of great interest to scholars of politics and public policy. Understanding how and why EPI is read in different ways by different actors in different jurisdictions and/or different stages of the policy cycle, is important, as these readings will inform different organizational or policy reforms which - we might reasonably expect - generate different policy outcomes. Analytically, comparative systems and policy-analytical approaches are well equipped to shed light on the interpretation and implementation of EPI.

This book will focus on a set of countries that are reputed to be pioneers in environmental policy, and on the EU, where we might expect that the normative core of EPI would be most likely to meet a high level of acceptance among policy makers and in society. Hence, here we may expect a high level of coherence between the normative definition of EPI and the positive meanings the concept is given in day-to-day political practice. Failure to achieve such coherence over time or compared to other jurisdictions should highlight the operational challenges implied in the concepts of sustainable development and EPI. 


\section{EPI AS A GOVERNING PROCESS}

\section{Different Analytical Perspectives}

Understood as a governing process, EPI refers to the development and application of different communicative, organizational and procedural instruments. In Chapter 2, these three sub-types are explained more fully. Essentially, communicative instruments set out visions and longer-term objectives which are supposed to guide more detailed reform efforts, while leaving it to individual governments and targeted sectors to develop concrete 'operations' for policy integration. Organizational instruments, by contrast, alter the context (for example, the rules and frameworks) in which policy decisions are made. Typically, these might seek to strengthen some actors (for example, environmental departments) at the expense of others, open up existing networks or even create completely new actors to push forward environmental concerns. Finally, procedural reforms seek to alter decision-making procedures (for example, law making, appraisal and budgeting).

Those working with a process interpretation of EPI (for example, Schout and Jordan 2005; Jordan and Schout 2006; Nilsson and Eckerberg, 2007: 3) are concerned less with pinning down the normative core of EPI in an abstract or conceptual sense, and more with describing and explaining the ways in which different actors interact to develop and implement positive interpretations of it in everyday policy-making situations. According to this view, EPI is 'a process through which "non" environmental sectors consider the overall environmental consequences of their policies, and take active and early steps to incorporate an understanding of them into policy making at all relevant levels of governance' (Jordan and Schout 2006: 66). What counts here is the political struggle between different normative conceptions. Hence the EEA's point about EPI being an 'ongoing process, not something that is simply "achieved" ' (EEA 2005b: 9).

Those that work with this interpretation distinguish between two broad understandings (or positive meanings) of EPI which may emerge in the heat of political decision making: a strong one and a weak one (Hill and Jordan 1993; Jordan and Schout 2006). 'Weak' EPI occurs when the sectors simply take environmental considerations 'into account', without giving them the 'principled priority' sought by Lafferty and his colleagues. The core of sectoral policies therefore remains essentially untouched, although some new routines may be added and the information upon which sectoral policy decisions are founded may be broadened. For example, the transport sector might discuss different ways of reducing the environmental burden of car transport (for example, by fitting catalytic converters or adopting 
alternative fuel sources), without radically challenging the underlying societal demand for more cars or more travel. 'Strong' EPI, by contrast, corresponds much more to Lafferty's (2004) reading of the normative core of the Brundtland Report, which would correspond to placing 'environmental considerations at the heart of decision making in other sectoral policies' (Haigh 2005, section 3.1-1). The commitment to minimize any contradictions between environmental and sectoral policies in the framework of EPI results 'giv[es] priority to the former over the latter' (Lafferty 2004: 13). ${ }^{5} \mathrm{~A}$ strong reading of EPI builds on an important insight with regard to the application of sustainable development: synergies between economic, social and environmental objectives (that is, the much emphasized 'winwin' solutions) may be constructed at an aggregate level over long periods, but may not be so obvious in everyday decision-making situations (compare Lenschow 2002c: 227ff), where harder choices may have to be made and priorities set.

This process of pulling and hauling (Dunsire 1993) amongst the various sectoral actors can be studied from different analytical perspectives. In this book we probe two of them: one which proceeds by comparing political systems; and another which is derived from a policy analysis approach and distinguishes between distinct phases of the policy-making process (for example, agenda setting, initiation, decision making, implementation, evaluation, revision) or between the different manifestations of policy instruments (for example, as ideas/text/speech, organization and procedure). Both of these can, in turn, be studied from an institutional, a political (that is actor-centred) and a cognitive perspective. The next two sub-sections discuss these in some detail.

\section{A Comparative Political Systems Perspective}

In our case studies (the chapters in Part III), we view EPI as a process: that is anchored in a political system; needs to be decided by political majorities; must be organized and managed; and finally, should be maintained (either through enforcement or through persuasion). The structure of the prevailing political system (institutions), the political context (politics) and the legal and administrative tradition of a polity (cognitive predispositions) are looked at 'in concert' in order (hopefully) to recognize the relevant dynamics for (effective) EPI. In this section we take stock of our knowledge of EPI processes from a political systems perspective. While the case studies in Part III analyse EPI processes in single political settings, Chapter 15 adopts a more comparative perspective.

As indicated above, our existing knowledge of EPI is very much limited to single, relatively isolated accounts of some instruments in the EU and 
some of its Member States. In the absence of more systematic analysis, these studies nonetheless suggest that there is considerable variation in terms of the national motivations for pursuing EPI, the implementing instruments adopted and the obstacles encountered. First, it reveals that EPI has been interpreted differently according to the way it has been embedded in national political discourses and legal systems. For instance, in the Netherlands, EPI is seen to require a deep-seated change in societal attitudes and the development of policy commitments between the state and civil society; Germany, on the other hand, focuses on its economic dimension and emphasizes the need to market environmental technologies and correct market failures; meanwhile, the UK initially approached it from a governance perspective, seeing it as a further impetus to strive for more coordinated and efficient government (Jordan and Lenschow 2000; Lenschow 2002a). In Sweden, EPI has mostly been interpreted in the wider, social context of sustainability (see Chapter 11). Meanwhile, the country studies in Lenschow (2002b) focused on Germany, Italy and the UK, and identified several obstacles to greater EPI. These range from the institutional structure of government (Germany), to administrative and legal culture (Italy and Germany), and high-level political will and leadership (Italy and the UK). These patterns suggest a great deal of path-dependency in terms of developing and implementing national strategies.

From an institutional perspective, the challenge of EPI, namely coordination across both horizontal and vertical boundaries in policy-making processes, is presumably compounded in political systems with a very high level of fragmentation. Hence, disintegrated policy making might be particularly evident in federal jurisdictions (like the USA, Germany, Australia and the EU in our sample). Implicit in this view is the notion that centralized (and strong) states are better able to ensure the successful implementation of sustainable development and EPI policies. A variant of this notion - in the sense of also focusing on the number of veto points in the decision-making system - follows from a comparison of Westminster-type systems (for example, the UK and Australia) and presidential systems (USA), or of single-party versus coalition governments (as these are typical in most parliamentary systems with proportional voting systems, for example, Germany, Sweden, Norway in our sample). A contrary position is adopted by parts of the implementation literature that suggest that decentralized systems may lead to stronger EPI as these are more capable of developing a feeling of 'ownership' at the grassroots level and hence bottom-up support for EPI. In short, from a comparative political systems perspective - distinguishing centralized and decentralized systems - we will be able to make a link to the 'top-down' versus 'bottom-up' debate that is ongoing in discussions of effective (environmental) policy making and 
governance. The conceptual discourse on EPI tends towards a 'top-down' approach, assuming in particular that an institutionalized normative anchor such as a constitutional commitment is required to ensure the prioritizing of the environment. The comparative country studies should contribute empirical evidence with which to test this claim.

By contrast, a political perspective focuses on political will and leadership. These are already recurring themes in the existing literature on EPI (OECD 2001; EEA 2005a; Jordan and Schout 2006). In this book, we deliberately look at states and political systems that are considered to be frontrunners in environmental policy, as we may assume that these countries have developed some response to the sustainable development and EPI discourse. More analytically, this allows us to investigate the impact of political leadership within a fairly homogeneous group.

Furthermore, differences in legal and administrative traditions affecting the third - or cognitive - dimension of policy making can be explored in explaining: (1) different approaches or strategies in adapting administrative practices to the task of EPI; and (2) different normative constraints in achieving EPI. The EEA $(2005 b)^{6}$ distinguishes between: the Germanspeaking systems, which rely heavily on legislation and law-obeying bureaucrats in administrations; the Anglo-Saxon system, where flexibility, adaptive capacity and the use of generalists is supposed to contribute to policy coordination and reform; the Nordic system, with its tendency towards consensual and cooperative governance; southern European systems, with highly legalistic, hierarchical and expert-based administrations; and finally, the former communist countries, where administrative tasks tend to rely heavily on external (party) control. By studying countries from the first three categories of legal and administrative culture, this book will be able to provide some insights with regard to the relevance of this factor.

To summarize, the existing literature suggests that EPI can be linked to a large bundle of institutional, political and cultural or cognitive issues. What has actually flowed from this research by way of suggesting concrete policy changes in the driving force sectors is by no means clear, however. One of the main purposes of the empirical chapters of this book is to review and compare systematically the experiences of implementing particular instruments (Part II) and bundles of instruments in particular political jurisdictions (Part III).

\section{A Policy Analysis Perspective}

From a policy analysis perspective, several analytical devices could be adopted. The phases of the policy cycle model are (despite some well-known 
weaknesses) a useful heuristic to investigate the level of commitment to EPI. EPI - if taken seriously - should shape every stage of decision making: sectoral policy makers would set the policy agenda with the environmental implications in mind; decision making would then be informed by environmental assessments; and policy feedback would cover any intended or unintended environmental consequences. Documenting the distribution of instruments empirically, within and across individual countries, will hopefully allow us to distinguish countries that establish a clear agenda for policy integration from countries that adopt EPI instruments in a more post hoc fashion. In order to ensure 'strong' EPI, the policy cycle model suggests that attention to environmental objectives needs to be given at the very start, that is, the credo of EPI should permeate the agenda-setting stage in sectoral policy making. Isolated EPI measures at later stages of the policy-making process may be capable of raising awareness and correcting individual decisions in the light of their negative environmental effects, but are very unlikely to give environmental thinking sufficient access to the 'mainstream' of sectoral policy to deliver greater EPI. At the same time, we should be able to distinguish systematic EPI efforts (that is, linked through the entire policy cycle) from more ad hoc attempts.

EPI instruments may also be ordered according to the way in which they manifest themselves. Communicative ones are relatively easy to implement but may not be followed up by action. Hence, they may be used for rhetorical purposes only. Organizational and (especially) procedural ones tend to intervene more actively in political and administrative routines; following an institutional logic, they should be adopted with greater reluctance. While this appears to correspond with the picture painted by existing studies, the chapters in Parts II and III will seek to reveal a much fuller picture. While the policy cycle perspective allows us to analyse the commitment of EPI over time, a systematic focus on the type of instrument alerts us to different forms of intervening in the process of EPI (forms that may be more or less deeply felt by the policy makers).

Also of analytical interest is the distinction between the institutional, political and cognitive impact of policy instruments, that is, our focus shifts from the form to the logic of change that is implied by them. This allows a direct link to be made with the political systems perspective and, more generally, to governance structures. The institutional and cognitive analytical interpretations relate to the need to embed EPI in the organizational set-up of government, and in the minds of policy makers and other relevant stakeholders. The crucial analytical distinction between the two explanations lies in the role attributed to political actors (and the degrees of freedom available for political choices). We will see that the institutional and cognitive logics often interact (for example, in governance frameworks that aim to 
facilitate communicative interaction). The governance structure that is most frequently associated with institutionalized communication is of course a network, which relies on there being an atmosphere of trusting collaboration between its members to be effective. In contrast, the political perspective tends to be less optimistic with regard to the effects of a stable institutional framework and the emergence of a normative framework for EPI. The presence of winners and losers and the resulting conflicts of interest call for powerful political interventions and a more hierarchical mode of governing. Such analysis of the institutional, political and cognitive factors in explaining the level of effectiveness of EPI requires a careful - case by case - approach, as policy instruments are not easily categorized in these terms. However, the existing literature does at least offer some guidance.

\section{An institutional perspective}

From an institutional perspective, EPI can be understood as a problem of policy coordination. The challenge of EPI arises from the fragmented nature of governmental systems, where policy sectors are institutionally separated (horizontal fragmentation) and where the coordination across different levels of government (vertical fragmentation) poses an additional problem, particularly in federal states like Germany, the USA, Australia and the EU. Here, the value of institution-building and organizational instruments or reforms would seem to be obvious. Building on an impressive body of research, Peters (1998: 296) defines coordination as a situation 'in which the policies and programmes of government are characterized by minimal redundancy, incoherence and lacunae'. But this headline definition can in turn be broken down into different coordination tasks. The influential Metcalfe scale (Metcalfe 1994), for instance, distinguishes nine tasks ranging from different sectors communicating with one another right through to a joint strategy. Chapter 3 shows how certain institutional and procedural arrangements can be associated with different levels or forms of coordination. Such arrangements may focus on the high level (cabinet, prime ministerial office) or on the lower, street levels of governments; they may also have a more strategic or a more operational character. Schout and Jordan argue that institutional (or 'administrative') change was a key element of Brundtland's prescription (see also Schout and Jordan 2005). They show that very many EPI instruments could be placed under this heading and explain why the existing literature is far from clear about how they could or should fit together.

\section{A political perspective}

While policy coordination via institutional and organizational means resonates well with the current discourse on 'good governance', the implementation of 'rational' structures and procedures can be a highly 
contentious matter, hence the importance of a political perspective. The bureaucratic politics literature ${ }^{7}$ sees political conflict arising from the development of distinct cultures and routines in the bureaucratic segments of an administration and from the 'rational' inclination of each part to protect its competences (and resources) as well as ways of doing things from the intervention of other parts. ${ }^{8}$ Such an inherently competitive structure poses a serious problem for those seeking to achieve greater policy integration. The obvious routes to achieving this involve lobbying the sectors from the outside and/or by exerting political leadership from above (hence the discussion of 'political will', 'commitment' and 'vision', particularly in the EEA's thinking - EEA 2005a/b). The extent to which political pressure from the apex of government and/or from society (whether as voters, activists or in other roles) are necessary prerequisites for EPI is an empirical question which is addressed in Parts II and III.

\section{A cognitive perspective}

A cognitive perspective searches for the source of the actor interests which stimulate the political conflicts noted above. According to Lenschow (2002a: 17), policy interests are often embedded in a 'frame of reference' or set of ideas 'which pre-structures the thinking within a policy sector'. The gradual, longer-term acceptance of new ideas can lead to a modification of actor interests and, possibly, also a reduction in the political conflicts noted above. Such ideas might relate to the economic and technological benefits of environmental protection, the potentially synergistic (win-win-win) relationship between the three pillars of sustainability, or - more deeply - to the life-sustaining role of environmental resources and hence their principled priority (most recently, Lafferty and Knudsen 2007). Those that adopt a learning perspective (for example, Hertin and Berkhout 2001; Nilsson 2005; Nilsson and Eckerberg 2007) are particularly interested in understanding the circumstances under which cognitive learning takes place within and across different 'frames of reference' (for example, sudden, unforeseen crises; exogenous shocks from outside the policy system; the gradual accumulation of worrying evidence, or - more manipulable - the accumulation of relevant knowledge in the early decision-making phase).

\section{EPI AS A POLICY OUTCOME}

Many environmentalists and, we suspect, Gro Harlem Brundtland, might well argue that concepts are only concepts, and process is only process; policy outcomes (that is, the influence of any EPI activity on the state of the environment and, ultimately, the sustainability or otherwise of human 
development) are what really matter in life. However, the measurement of outcome effectiveness is a very difficult task, and one which is not helped by the relative immaturity of this particular sub-field of evaluation research (but see Knaap and Kim 1998).

First, one needs to decide what counts as a 'good' or 'satisfactory' outcome and what outcome lies 'below standard'. In other words, are there certain basic benchmarks - that is, certain basic environmental quality standards or ecological support functions - that must be addressed regardless of the social and environmental cost (Lafferty and Knudsen 2007), before the policy 'game' of trading off begins? Knowing that the setting of benchmarks can be a scientifically complex and highly politicized process, it cannot be assumed that securing them actually promotes long-term sustainability, however. In other words, the measuring rod for assessing outcome effectiveness lies in the eyes of the beholder, and this causes serious methodological problems.

In the case of EPI, the main 'subject' - that is, the state of the environment now and in the long run - is a highly complex matter, affected by a multitude of factors. Objective and reliable data is hard to come by (Scruggs 2003: 205). Moreover, as we will see in this book, there are many different instruments which could be applied to deliver EPI, and these may well interact with one another, as well as background factors like economic and technological development, basic features of democracy (for example, veto points, democratic style), the prevailing regulatory culture and levels of public opinion, to name just a few. From an analytical perspective, the existence of so many potential causal factors and implementing instruments implies that causality cannot easily be determined.

From a policy maker's perspective, this creates a situation where the outcome of any single instrument can hardly be known with any degree of certainty. To address this requires inter alia a highly sophisticated understanding of: (1) the way in which any single EPI instrument operates and what behavioural impacts it generates within 'non' environmental sectors; (2) the manner in which different EPI instruments interact; (3) how instruments that were adopted at various levels of governance cohere (for example, strategic plans decided in the prime minister's office and consultation practices at sub-national level); (4) the manner in which all the instruments used are embedded in a larger political, economic and social context; and (5) how well all the instruments and interrelations effectively translate into policy outcomes.

In order to develop such a sophisticated understanding, two different approaches are potentially available: complex forms of decomposition analysis and detailed case studies of individual policy interventions. In this book, we will take the middle ground, whilst remaining cognisant of the 
difficulty of arriving at causal explanations. First, we will investigate the merits of a range of different EPI instruments ${ }^{9}$ (Part II). In order to isolate these merits we will approach them from a comparative angle. Based on a review of the existing literature, we also aim to identify some of the conditions under which these instruments work. Second, we then look at how these instruments have been applied (both individually and together) in different political contexts. In order to control for too much complexity, this contextual analysis is done in single jurisdictions (Part III). When taken together, we hope they will offer some comparative insights into the extent to which each jurisdiction has considered EPI from an outcome perspective, what steps (if any) it has taken to measure and evaluate outcome effectiveness, and what it has learned from such activities. We shall report on the outcome of this approach in our concluding chapter.

\section{THE STRUCTURE OF THE BOOK}

The concept of EPI achieved far greater prominence and much greater conceptual coherence after it had been highlighted in the 1987 Brundtland Report. There can be no denying that the potential scope of EPI is very wide indeed, with a vertical (multi-level governance) and a horizontal (cross-sectoral) dimension on the one hand, and a continuing relevance right across the policy cycle on the other. In a sense, EPI is very much like its 'mother concept' - sustainable development - in that it seeks to be 'everywhere' in the policy system. However, this is a rather precarious position to be in when the firewalls between sectors are strong and political leadership from politicians and prime ministers is relatively ephemeral.

Were EPI ever to be implemented in the manner sought by Brundtland, it would involve a profound innovation in the orientation and structures of environmental policy making. So, to what extent have our seven jurisdictions managed to engineer such an innovation in their policy-making structures and decision-making systems? The literature on sustainable development is already voluminous and that on EPI is growing fast. Despite their obvious conceptual interconnectedness, these two literatures are relatively poorly integrated, both due to their spatial appeal (EPI seems to be a particularly European concern, whereas sustainable development has a much broader application) and distinct levels of analysis (many empirical accounts of EPI tend to be relatively narrow, covering it from the perspective of particular sectors and/or countries).

Our approach is to inspect the toolbox of available instruments and then investigate how they have - or have not - been adopted to implement EPI. Our analysis commences in Chapter 2, with a panoramic analysis of the 
deployment of the main implementing instruments in 30 OECD countries. This chapter seeks to highlight the most important geographical and temporal patterns in a manner which is absent from the existing literature. In Part II we delve further into the toolbox by looking at five main instruments. Each of the five chapters follows the same format, namely a brief introduction to and historical summary of the instrument in question, a description of its conceptual underpinnings and then an assessment of its performance. ${ }^{10}$ In Part III, we present the national experience of deployment. Again, these seven chapters have been written to fit a standard format which includes a brief historical summary, a review of how each instrument has been implemented and an assessment of its performance. Finally, in Part IV we attempt to identify broad patterns and future research needs in this new and important area of environmental policy analysis.

\section{NOTES}

1. The Brundtland committee's report did not invent the phrase 'sustainable development'; the interdependence of ecological and developmental goals had been discussed as long ago as the 1972 UN conference in Stockholm (Alker and Haas 1993: 5-6; Lenschow 2002a: 5). Brundtland's greatest contribution was to bring together the (now very well known) triad of economic, social and environmental issues under the umbrella of sustainable development.

2. See also EEA (2007) and UNEP (2007).

3. But see Nilsson and Eckerberg (2007) on Sweden, Hovden and Torjussen (2002) on Norway and Jordan (2002) on the UK.

4. The way in which 'development' is used here is broadly synonymous with 'social'. This highlights another source of terminological confusion, as neither 'social' nor 'development' are entirely separate from the 'economic' as all economic activities are a special form of social interactions (which may go through a process of development or change). Hence the notion that there are 'pillars' of activity that can be (and have been) kept apart is itself a political and social construction.

5. Elsewhere, Lafferty (2002: 2$)$ argues that 'the general environmental . . element [that is, pillar] of sustainable development is the most fundamental - the one without which the concept loses its distinctive meaning' (emphasis added).

6. The EEA report (EEA 2005b) speaks of 'administrative cultures' (our emphasis), which is broadly synonymous with our term 'tradition'.

7. For the classical view, see Allison (1971). For an application to EPI in the EU, see Schout and Jordan (2005) and Jordan and Schout (2006).

8. As Allison (1971) was at great pains to point out, where you stand (on an issue) depends on where you sit (in an organization).

9. It is instructive that recent comparative studies of the policy determinants of environmental performance have tended to analyse performance at an aggregate level (that is, of all policy and non-policy interventions), rather than in terms of individual policies or policy instruments. For good summaries of why the latter might be very difficult to produce, see Parsons (1995: 600-613), Weale (1992) and Knaap and Kim (1998).

10. Given obvious space constraints, we decided not to include a separate chapter on 'new' environmental policy instruments (NEPIs) (for example, voluntary agreements, ecotaxes and environmental management systems), because these are already extensively addressed in the existing literature (Jordan et al. 2003; Jordan et al. 2005). 


\section{BIBLIOGRAPHY}

Alker, H. and P. Haas (1993), 'The rise of global ecopolitics', in N. Coucri (ed.), Global Accord: Environmental Challenges and International Responses, Cambridge, MA and London: MIT Press.

Allison, G. (1971), Essence of Decision: Explaining the Cuban Missile Crisis, Boston, MA: Little Brown.

Dunsire, A. (1993), 'Modes of governance', in J. Kooiman (ed.), Modern Governance: New Government-Society Interaction, London: Sage.

EEA (European Environment Agency) (2003), Europe's Environment: The Third Assessment (Full report), Copenhagen: European Environment Agency.

EEA (European Environment Agency) (2005a), Environmental Policy Integration in Europe: State of Play and an Evaluative Framework, Technical Report, No. 2/2005, Copenhagen: European Environment Agency.

EEA (European Environment Agency) (2005b), Environmental Policy Integration in Europe: Administrative Culture and Practices, Technical Report, No 5/2005, Copenhagen: European Environment Agency.

EEA (European Environment Agency) (2007), Europe's Environment: The Fourth Assessment ( Full report), Copenhagen: European Environment Agency.

Haigh, N. (ed.) (2005), Manual of European Environmental Policy: The EU and Britain, Leeds: Maney Publishing.

Hertin, J. and F. Berkhout (2001), 'Ecological modernization and EU environmental policy integration', Journal of Environmental Policy and Planning, 5 (1): 39-56.

Hession, M. and R. Macrory (1998), 'The legal duty of environmental integration: commitment and obligation or enforceable right?' in T. O'Riordan and H. Voisey (eds), The Transition to Sustainability: The Politics of Agenda 21 in Europe, London: Earthscan.

Hill, J. and A.J. Jordan (1993), 'The greening of government: lessons from the White Paper process', ECOS, 14 (3-4): 3-9.

Hovden, E. and S. Torjussen (2002), 'Environmental policy integration in Norway', in W. Lafferty, M. Nordskag and H. Aakre (eds), Realizing Rio in Norway: Evaluative Studies of Sustainable Development, Oslo: ProSus.

Jacob, K. and A. Volkery (2004), 'Institutions and instruments for government selfregulation: environmental policy integration in a cross-country comparison', Journal of Comparative Policy Analysis, 6 (3): 291-309.

Jordan, A.J. (2002), 'Efficient hardware and light green software? Environmental policy integration in the UK', in A. Lenschow (ed.), Environmental Policy Integration: Greening Sectoral Policies in Europe, London: Earthscan.

Jordan, A.J. (2008), 'The governance of sustainable development: taking stock and looking forwards', Environment and Planning C, 26 (1): 17-33.

Jordan, A. and A. Lenschow (2000), 'Greening the European Union: What can be learned from the "leaders" of EU environmental policy?' European Environment, 10 (3): 109-120.

Jordan, A.J. and A. Schout (2006), The Coordination of the European Union: Exploring the Capacities for Networked Governance, Oxford: Oxford University Press.

Jordan, A.J., Wurzel, R. and Zito, A. (eds) (2003), 'New' Instruments of Environmental Governance? National Experiences and Prospects, London: Frank Cass.

Jordan, A., Wurzel, R. and A. Zito (2005), 'The rise of "new" policy instruments in 
comparative perspective: has governance eclipsed government?' Political Studies, 53 (3): 477-496.

Knaap, G. and T. Kim (eds) (1998), Environmental Program Evaluation, Urbana: University of Illinois Press.

Lafferty, W. (2002), Adapting Governance Practice to the Goals of Sustainable Development, paper presented at an OECD PUMA seminar on Improving Governance for Sustainable Development, 22-23 November, Paris: OECD.

Lafferty, W. (2004), 'From environmental protection to sustainable development: the challenge of decoupling through sectoral integration', in W. Lafferty (ed.), Governance for Sustainable Development: The Challenge of Adapting Form to Function, Cheltenham: Edward Elgar.

Lafferty, W. and E. Hovden (2003), 'Environmental policy integration: towards an analytical framework', Environmental Politics, 12 (3): 1-22.

Lafferty, W. and J. Knudsen (2007), The Issue of 'Balance' and Trade-offs in EPI: How Will We Know EPI When We See It? EPIGOV Working Paper, 31 January, Berlin: Ecologic.

Lenschow, A. (2002a), 'Greening the European Union: an introduction', in A. Lenschow (ed.), Environmental Policy Integration: Greening Sectoral Policies in Europe, London: Earthscan.

Lenschow, A. (ed.) (2002b), Environmental Policy Integration: Greening Sectoral Policies in Europe, London: Earthscan.

Lenschow, A. (2002c), 'Conclusion: what are the bottlenecks and where are the opportunities for greening the EU?' in A. Lenschow (ed.), Environmental Policy Integration: Greening Sectoral Policies in Europe, London: Earthscan.

Liberatore, A. (1997), 'The integration of sustainable development objectives into EU policy making', in S. Baker, M. Kousis, D. Richardson and S. Young (eds), The Politics of Sustainable Development, London: Routledge.

Metcalfe, L. (1994), 'International policy coordination and public management reform', International Review of Administrative Studies, 60: 271-290.

Nilsson, M. (2005), 'Learning, frames, and environmental policy integration: the case of Swedish energy policy', Environment and Planning C, 23: 207-226.

Nilsson, M. and K. Eckerberg (eds) (2007), Environmental Policy Integration in Practice, London: Earthscan.

Nollkaemper, André (2002), 'Conceptions of the integration principle in international environmental law', in A. Lenschow (ed.), Environmental Policy Integration: Greening Sectoral Policies in Europe, London: Earthscan.

OECD (Organisation for Economic Cooperation and Development) (2001), Governance For Sustainable Development: Five OECD Case Studies, Paris: OECD.

OECD (Organisation for Economic Cooperation and Development) (2002), Improving Policy Coherence and Integration For Sustainable Development: A Checklist, Paris: OECD

Pallemaerts, M., D. Wilkinson, C. Bowyer, J. Brown et al. (2006), Drowning in Process? The Implementation of the EU's 6th Environmental Action Programme, Report for the European Environmental Bureau, London: IEEP.

Parsons, W. (1995), Public Policy, Aldershot: Edward Elgar.

Peters, G.B. (1998), Managing Horizontal Government: The Politics of Coordination, Research paper No. 21, Ottawa: Canadian Centre for Management Development.

Schout, A. and A.J. Jordan (2005), 'Coordinated European governance: selforganizing or centrally steered?' Public Administration, 83 (1): 201-220.

Scruggs, L. (2003), Sustaining Abundance, Cambridge: Cambridge University Press. 
UNCED (United Nations Commission on Environment and Development) (1992), Agenda 21, New York: United Nations.

UNEP (United Nations Environment Programme) (2007), Global Environmental Outlook: GEO 4, Nairobi: UNEP.

Vogel, D. (2005), 'The hare and the tortoise revisited', in A. Jordan (ed.), Environmental Policy in the European Union, 2nd edn, London: Earthscan.

WCED (World Commission on Environment and Development) (1987), Our Common Future, Oxford: Oxford University Press.

Weale, A. (1992), 'Implementation failure: a suitable case for review?' in E. Lykke (ed.), Achieving Environmental Goals, London: Belhaven Press.

Weale, A. and A. Williams (1992), 'Between economy and ecology? The single market and the integration of environmental policy', Environmental Politics, 1 (4): 45-64. 